\title{
Evaluación de la mortalidad de bosques de ñirre (Nothofagus antarctica) en la Patagonia chilena mediante imágenes Landsat TM y ETM+
}

\author{
Forest decline evaluation in Antarctic Beech Forests (Nothofagus antarctica) \\ in Chilean Patagonia by using Landsat TM and ETM+
}

\section{Rafael M Navarro Cerrillo ${ }^{a *}$, Mauricio Rosenfeld ${ }^{b}$, Jaime Pérez-Aranda ${ }^{a}$, Eva Padrón ${ }^{a}$, José R Guzmán ${ }^{a}$, Rocío Hernández Clementea ${ }^{a}$ Luis González}

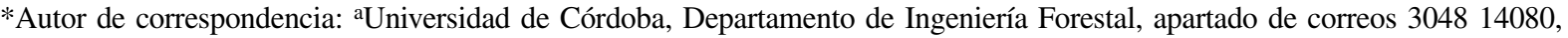
Córdoba, España, tel.: 34-957-218657, fax: 34-957-218563, ir1nacer@uco.es

bUniversidad de Magallanes, Facultad de Ciencias, Escuela de Ciencias y Tecnologías Agropecuarias, Punta Arenas, Chile. ${ }^{c}$ Universidad de Chile, Facultad de Ciencias Forestales, Departamento de Manejo de Recursos Forestales,
\end{abstract} La Pintana, Santiago, Chile.

\begin{abstract}
SUMMARY
Antarctic beech forests (Nothofagus antarctica (G. Forst.) Oerst.) have shown a major decline process in the past few decades, together with an important lack of specific studies on this type of forest. The aim of this work was to create cartography of the surface of Antarctic beech forests and to evaluate decline levels in the XII Region of Chile. A study area was selected between the cities of Puerto Natales and Punta Arenas (latitudes 50 $40^{\prime}$ 'S to $52^{\circ} 40^{\prime} \mathrm{S}$ ) and from latitudes $60^{\circ} 15^{\prime} \mathrm{W}$ to $74^{\circ} 15^{\prime} \mathrm{W}$, where a random stratified sampling was carried out in 68 plots, in which the forest cover, mortality, height, normal diameter and regeneration were measured. Using two Landsat images (1986-2002), the study area was classified in terms of vegetation cover and forest mortality, by means of the normalized vegetation index (NDVI). The forests in this study area are characterized by their high density, and, in over half their surface $(27,873 \mathrm{ha})$ they exhibit some degree of mortality, with 7,585 ha of forest completely affected. The distribution of the mortality in Antarctic beech on the period 1986-2002 showed an improvement on forests condition, which seems to corroborate the hypothesis of a change on perturbation pattern as the major reason for this forest decline process.
\end{abstract}

Key words: forest decline, remote sensing, spatial pattern, temporal change.

\section{RESUMEN}

Los bosques de ñirre (Nothofagus antarctica) han experimentado en las últimas décadas un importante proceso de mortalidad. El objetivo de este trabajo fue elaborar una cartografía de las masas de ñirre en función de la fracción de cabida cubierta del dosel arbóreo y el nivel de mortalidad en la XII Región de Chile. En una zona entre las ciudades de Puerto Natales y Punta Arenas $\left(50^{\circ} 40^{\prime}-52^{\circ} 40^{\prime} \mathrm{S}\right.$ y $69^{\circ} 15^{\prime}-74^{\circ} 15^{\prime}$ O) se realizó un muestreo estratificado en 68 parcelas, donde se midieron: fracción de cabida cubierta, mortandad del arbolado, altura, diámetro normal (DAP) y regeneración. Mediante clasificación de dos imágenes Landsat TM (1986) y ETM+ (2002) se estudiaron el estado de las masas de ñirre y la evolución de la mortandad en un periodo de 16 años, utilizando el índice de vegetación normalizado (NDVI). En el año 2002 los bosques de ñirre se caracterizaban por una elevada fracción de cabida cubierta, tallas y diámetros medios, y una escasa regeneración. Más de la mitad de la superficie de estudio (casi 28.000 ha) presentaba algún grado de mortandad del arbolado, con 7.585 ha de bosques totalmente muertos. El patrón de mortandad, por comparación con el estado del arbolado en 1986, indicó una tendencia a mejorar el estado del arbolado en los últimos 16 años, lo cual parece confirmar la hipótesis de que los procesos de mortandad en esta especie no están asociados a un cambio en el patrón climático en la zona, sino más bien a la modificación del régimen de perturbaciones.

Palabras clave: mortalidad, teledetección, índice de vegetación, patrón espacial, cambio temporal.

\section{INTRODUCCIÓN}

El ñirre (Nothofagus antarctica (G. Forst.) Oerst.) es un pequeño árbol de hasta $15 \mathrm{~m}$ de altura, aunque es frecuente encontrarlo con porte arbustivo en zonas de elevada altitud, zonas de ecotono con la estepa y en sitios de extrema humedad y mal drenaje donde va adoptando progresivamente carácter de planta achaparrada (Krummholz) (Ramírez et al. 1985). La especie puede formar rodales puros o mixtos, principalmente con Nothofagus pumilio (Poepp. et Endl.) Krasser. (lenga), aunque también se asocia con Nothofagus betuloides (Mirb.) Oerst., Araucaria araucana (Mol.) Dock., Fitzroya cupressoides (Mol.) Im. Johnst. y Pilgerodendron uviferum (D. Don.) 
Florin (Donoso 1993, Veblen et al. 1996a). En hábitats más favorables, protegidos del viento, con mayor humedad y suelos bien drenados y fértiles, alcanza porte arbóreo y puede dar lugar a formaciones puras. Se distribuye desde la VII Región (34 ${ }^{\circ} \mathrm{S}$ ) hasta el archipiélago de Cabo de Hornos (XII Región) (56 $\mathrm{S}$ ), apareciendo en los tipos forestales (Donoso 1981) Roble-Hualo, Coigüe-Raulí-Tepa, Coigüe de Magallanes y Lenga.

El término "decaimiento forestal" es ampliamente utilizado para describir el estado de deterioro de los ecosistemas forestales, incluyendo cambios metabólicos, problemas de reproducción, prematura senescencia de la hoja, decoloración, disminución y alteraciones del crecimiento, alteraciones de las ramas y de la morfología de la copa, pérdida de follaje, y finalmente la muerte del árbol (Innes 1993). Los procesos de mortalidad han sido estudiados con bastante profundidad en los últimos años, proponiéndose numerosas hipótesis para su explicación: malas prácticas silviculturales, toxicidad por aluminio en suelos ácidos, lixiviación de nutrientes minerales por la acción de la lluvia ácida, contaminación debida a ozono/fotoquímica, contaminación por dióxido de azufre y óxidos de nitrógeno, cambio climático, desequilibrios nutricionales como consecuencia de excesos o déficit de nitrógeno en el suelo (Innes 1993). En los años 70 y 80 se generalizó la hipótesis del multiestrés (Manion 1991). Esta hipótesis enfatiza la interacción entre factores abióticos y bióticos (por ejemplo, clima, insectos y hongos) y diferentes formas de estrés antrópico, por ejemplo contaminación o prácticas silviculturales inadecuadas (Klap et al. 2000).

La mortandad de la vegetación provoca una serie de transformaciones en la estructura, morfología y fisiología del rodal, que incluyen alteraciones en los pigmentos que absorben la luz, en la estructura interna de la hoja y en el contenido de humedad a nivel celular (Chuvieco 1996) que modifican la respuesta espectral de las cubiertas vegetales (Ekstrand 1994). La variación espectral causada por los fenómenos relacionados con el decaimiento forestal permite utilizar la teledetección como una buena herramienta en la detección y la cuantificación de este tipo de procesos en grandes superficies (Chuvieco 1996). En los últimos años se han desarrollado trabajos en los que la teledetección, y más concretamente las escenas Landsat 7 ETM+, se utilizan para cartografiar zonas afectadas por procesos de decaimiento (Heikkilä et al. 2002, Wulder et al. 2006).

Los ecosistemas que incluyen especies del género Nothofagus han sido poco estudiados mediante el uso de teledetección, aunque existen algunos trabajos previos (Lara et al. 1995, SIAN 1998, Collado 2001, Kurtz et al. 2001, Segura y Trincado 2003). Respecto a estudios más específicos sobre $N$. antarctica, puede destacarse el trabajo realizado en ciertas zonas de reducida superficie de la XII Región con imágenes SPOT (Willhauck 2000) que incluyen también a otras especies del género Nothofagus, y los realizados con imágenes Landsat TM y ETM+ en
Chile y Argentina (Dollenz y Santana 2000, Arqueros et al. 2000).

Durante las últimas décadas del siglo $\mathrm{XX}$ se han descrito varios procesos de mortalidad en especies propias del bosque patagónico en Chile y Argentina (Veblen y Lorenz 1988, Rebertus et al. 1993). Los episodios de mortandad en este tipo de bosques se han atribuido a diferentes causas tales como alteraciones globales del clima (Villalba y Veblen 1998), senescencia (Veblen et al. 1996a), herbivoría (Veblen et al. 1996b), agentes bióticos (Veblen et al. 1996a), cambios en el patrón de incendios (Veblen y Lorenz 1988, Kitzberger y Veblen 1999) o a la interacción entre varios factores (Veblen et al. 2004).

La importancia ecológica de los bosques de $N$. antarctica y la progresiva generalización de procesos de mortandad hacen necesario desarrollar métodos de cartografía forestal que permitan caracterizar este tipo de ecosistema según valores de cobertura y mortalidad. El objetivo de este trabajo es estudiar el uso de imágenes Landsat 5 TM y 7 ETM+ para cartografiar los bosques de ñirre en función de la fracción de la cabida cubierta y la mortandad, y evaluar el cambio experimentado en la mortalidad del arbolado en estos bosques durante el periodo 1986-2002, en un área entre las provincias de Última Esperanza y Magallanes (Región de Magallanes y Antártica Chilena).

\section{MÉTODOS}

Zona de estudio. El área de estudio está situada en la Patagonia chilena, en las provincias de Magallanes y Última Esperanza (figura 1), entre las ciudades de Puerto Natales

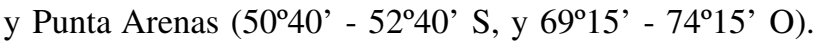
$\mathrm{El}$ relieve se caracteriza por grandes valles glaciales, con un paisaje suave a ondulado, con pendientes inferiores al $20 \%$, con transiciones a las cadenas montañosas con rangos de elevación entre 600 y $700 \mathrm{~m}$. El clima corresponde a uno trasandino con degeneración esteparia. Las precipitaciones se distribuyen a lo largo de todo el año, con montos anuales entre 250 y $400 \mathrm{~mm}$. La continentalidad hace que las temperaturas en general desciendan, encontrándose valores medios anuales de $6{ }^{\circ} \mathrm{C}$ a $7{ }^{\circ} \mathrm{C}$. Hacia el Este el clima evoluciona hacia las estepas frías, donde las precipitaciones continúan disminuyendo a medida que la zona se aleja de la cordillera patagónica, generándose montos anuales que varían desde $500 \mathrm{~mm}$ en el sector norte cercano a la cordillera hasta unos $250 \mathrm{~mm}$ en el extremo oriental del Estrecho de Magallanes y en la parte norte de Tierra del Fuego. La temperatura media anual oscila entre $8{ }^{\circ} \mathrm{C}$ y $9{ }^{\circ} \mathrm{C}$ (INIA 1989). Toda la provincia de Última Esperanza se encuentra sometida a la acción de fuertes vientos, especialmente en primavera y verano, que inciden notablemente sobre el crecimiento y la estabilidad de los bosques. Los suelos pertenecen al gran grupo de los suelos pardo podzólicos, derivados de sedimentos glaciales, mezclados con cenizas volcánicas presentes en 
todos los horizontes y sin evidencias de erosión, ácidos, de profundidad variable, en algunos casos con problemas de drenaje (áreas de fondo de valle) y muy humificados (mor) (Diaz y Roberts 1960).

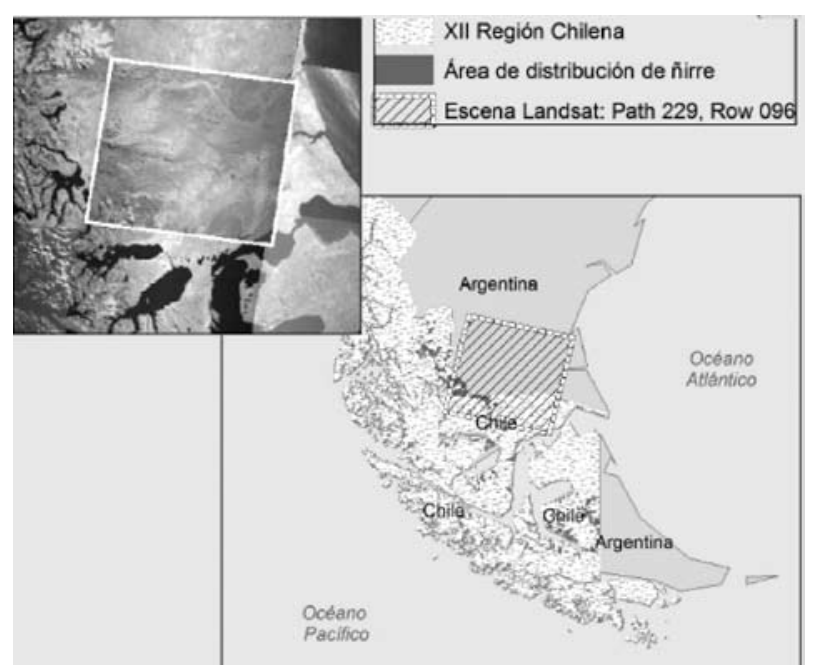

Figura 1. Localización del área de estudio.

Location of the study area.

La vegetación existente corresponde a la formación vegetal denominada Bosque Magallánico Caducifolio, conformando una agrupación heterogénea en estructura y fisonomía (Pisano 1997) y con una transición progresiva hacia la estepa de gramíneas. Las formaciones de ñirre se distribuyen desde el límite altitudinal de la vegetación arbórea hasta formaciones achaparradas en turberas y terrenos bajos inundables (CONAF-CONAMA 1997). En la zona de estudio dominan las formaciones arbustivas de ñirre con sotobosque de mata negra (Juniellia tridens (Lag.) Mold.), asociada con calafate (Berberis buxifolia Lam.), chacal (Discaria chacaye (G. Don.) Tortosa) y mata verde chica (Baccharis magellanica (Lam.) Pers.), apareciendo en la transición a las zonas esteparias el coirón (Festuca gracillima Hook.) y otras gramíneas esteparias, mientras en las hidrófilas el estrato arbustivo está ampliamente dominado por calafate (Pisano 1997). La mayor parte de estas formaciones ha sufrido un importante impacto antrópico, principalmente incendios y aprovechamiento ganadero extensivo.

Diseño del inventario forestal. El inventario realizado consistió en un muestreo estratificado al azar para evitar el uso de una malla u otro elemento que definiera el inventario de una forma estricta y dificultase la labor de localización de las parcelas. La estimación de la intensidad de muestreo y el tamaño de la muestra se diseñó a partir de la variable biofísica fracción de cabida cubierta (fcc), con un error muestral del 7,5\% y unos límites de confianza del $95 \%$, a partir de la fórmula de González et al. (1993), obteniéndose un total de 40 parcelas. A ese número se añadieron 28 parcelas adicionales, quedando un total de 68 parcelas.

Las parcelas de inventario eran de forma cuadrada de $90 \mathrm{~m}$ de lado $\left(8.100 \mathrm{~m}^{2}\right)$, concordantes con la resolución espacial de las imágenes Landsat 7 ETM+ de 30 $\mathrm{m}$, con lo que cada parcela ocupaba nueve píxeles en la imagen. Cada parcela se georreferenció por medio de un GPS (Garmin GPS 76), tomando como coordenada de la parcela el centro de la misma. El trabajo de campo tuvo una duración total de 23 días distribuidos entre el 15 de enero y el 1 de marzo de 2004. Las variables medidas en cada parcela fueron las siguientes:

- Mortandad de la masa: se establecieron tres categorías de mortandad, no afectado (vegetación sana), afectación media (pies con algunas ramas muertas) y afectación alta (copas con abundantes ramas muertas en casi todos los pies o vegetación muerta).

- Fracción de cabida cubierta (fcc): estimada mediante la proyección de copas y clasificada en las categorías de bosques claros con pies dispersos de ñirre (40-60\%), bosques defectivos (60-80\%) y bosques densos (80-100\%). Se consideraron ñirrantales a las unidades de vegetación en las que el ñirre estaba presente con una fracción de cabida cubierta igual o superior al $40 \%$ de la cobertura total.

- Altura y diámetro normal (DAP) a 1,30 m del suelo de los cinco árboles más cercanos al punto central de la parcela. La altura se midió con un hipsómetro (Suunto) y el diámetro con forcípula. Se consideraron árboles a todos los individuos mayores de $5 \mathrm{~cm}$ de DAP.

- La regeneración se midió en cuatro subparcelas tomadas al azar dentro de cada parcela, definidas lanzando una cuadrícula metálica de $1 \mathrm{~m}$ de lado ( $1 \mathrm{~m}^{2}$ de superficie). En cada subparcela se contaron todos los individuos de DAP $<5 \mathrm{~cm}$, separando los que procedían de semilla (brinzales) de los procedentes de reproducción vegetativa (chirpiales). La diferenciación entre estos tipos de regeneración se hizo por criterio visual (Silla et al. 2002).

Caracterización de las formaciones de ñirre. La caracterización de los ñirrantales se realizó según los criterios establecidos por la estrategia para la Observación Global de Cambios en la Cubierta Forestal (GOFC 1999), considerando como variable principal la fracción de cabida cubierta y como variables secundarias la mortalidad del arbolado y la regeneración. La caracterización propuesta es un paso previo al proceso de clasificación de la imagen y al desarrollo de la cartografía de la mortalidad.

Cartografía de la mortandad en los ecosistemas de ñirre. Las imágenes seleccionadas para el estudio correspondieron a la escena Path 229 Row 096 del sensor Landsat 5 TM de fecha 16 de enero de 1986, y la imagen Path 
229 Row 096 del sensor Landsat 7 ETM+ de fecha 5 de febrero de 2002, suministradas por la CONAF. Se obtuvo como información complementaria un modelo digital de elevaciones de 90 m de resolución espacial (SRTM 90 m; http://glcfapp.umiacs.umd.edu:-8080/esdi/index.jsp).

Las imágenes disponían de una corrección geométrica previa. La corrección radiométrica se realizó usando la fórmula de Markham y Barker (1986). Posteriormente se procedió a una normalización radiométrica relativa de la imagen de 1986 según el método de regresión lineal (Lo et al. 1986) para pasar a datos de reflectancia. Este método permite establecer una normalización atmosférica empírica tomando la imagen de 2002 como referencia por ser la de atmósfera más clara. Este método se basa en determinar una serie de cubiertas que no cambian con el tiempo (asfalto, agua y suelo desnudo) para estimar los coeficientes de sesgo y ganancia que permitieron hacer una correspondencia de las dos imágenes soslayando el efecto atmosférico.

Una vez completada la corrección de las imágenes se hizo un estudio de cambio del estado de la vegetación entre la imagen del año 1986 y la del año 2002 mediante la técnica de comparación posclasificación. Se procedió a clasificar la imagen de 2002 utilizando el índice normalizado de vegetación (NDVI en sus siglas en inglés) (Chuvieco 1996). El índice se calculó para las 68 parcelas de entrenamiento, como media de los nueve píxeles correspondientes a la superficie de la parcela $\left(8.100 \mathrm{~m}^{2}\right)$. A partir de los valores de campo se calcularon dos ecuaciones de regresión tomando como variables dependientes la fracción de cabida cubierta y la mortandad, y como variable independiente el NDVI. En la imagen correspondiente al año 1986 se aplicaron dichas ecuaciones para clasificar la imagen de acuerdo a las dos variables consideradas (Song et al. 2001).
Análisis estadístico. Los modelos de predicción de las variables fracción de cabida cubierta y niveles de afectación se realizaron mediante regresión, utilizando como medidas relativas de la bondad del ajuste el coeficiente de correlación $r$, el coeficiente de determinación $R^{2}$ y el error estándar de estimación $S E$. Las pruebas de la bondad del ajuste se hicieron analizando la varianza para contrastar la significación del estadístico $R^{2}$ mediante el cálculo del estadístico F y su nivel de significación $P$. No fue posible realizar un proceso de validación de la cartografía al no contar con suficiente número de puntos en campo.

Se verificó que los valores del índice de vegetación (NDVI) obtenidos en la clasificación del año 2002 cumplían los requisitos de normalidad y de homocedasticidad. La normalidad se comprobó mediante la prueba de KolmogorovSmirnov y la homocedasticidad por la prueba de Levene. Una vez realizada la comprobación de los requisitos básicos de los datos, se procedió a un análisis de la varianza (ANOVA) de un factor para las variables. Cuando el análisis de la varianza fue significativo se realizó una prueba de Tukey de comparación múltiple de las medias para un nivel de significación del 5\% $(P \leq 0,05)$.

El análisis estadístico de los datos se realizó con el paquete estadístico SPSS 8.0. El software usado para el análisis de las imágenes fue ERDAS Imagine 8.6 y ArcInfo versión 8.3.

\section{RESULTADOS}

Caracterización de las formaciones de ñirre. Se observó una proporcionalidad entre el aumento en la cobertura y la reducción del diámetro normal y el aumento de la altura (cuadro 1), lo cual supone que los árboles son más esbeltos a medida

Cuadro 1. Caracterización de los bosques de ñirre en función de la fracción de cabida cubierta y la mortalidad en la provincia de Magallanes y Última Esperanza (Patagonia, Chile). Valores expresados como media \pm error estándar.

Typification of Nothofagus antarctica forests in terms of forest cover and mortality in Magallanes and Ultima Esperanza provinces (Patagonia, Chile). Values expressed as mean \pm standard error.

\begin{tabular}{|c|c|c|c|c|c|}
\hline \multirow[b]{2}{*}{ Clases* } & \multirow[b]{2}{*}{$\begin{array}{c}\mathrm{N}^{\mathbf{o}} \text { de } \\
\text { parcelas }\end{array}$} & \multirow{2}{*}{$\begin{array}{c}\text { Altura } \\
\text { media** } \\
(\mathrm{m})\end{array}$} & \multirow{2}{*}{$\begin{array}{l}\text { Diámetro } \\
\text { normal } \\
(\mathrm{cm})\end{array}$} & \multicolumn{2}{|c|}{ Regeneración (plantas/ha) } \\
\hline & & & & $\begin{array}{c}\text { Regeneración } \\
\text { vegetativa }\end{array}$ & Plántulas \\
\hline \multicolumn{6}{|c|}{ Fracción de cabida cubierta } \\
\hline $40-60 \%$ & 21 & $3,2 \pm 2,1$ & $20,7 \pm 4,3$ & $535 \pm 1.344$ & $833 \pm 1.692$ \\
\hline $60-80 \%$ & 28 & $4,9 \pm 3,2$ & $19,1 \pm 7,2$ & $625 \pm 1.102$ & $267 \pm 623$ \\
\hline $80-100 \%$ & 19 & $5,1 \pm 2,4$ & $15,5 \pm 6,3$ & $460 \pm 951$ & $657 \pm 1.341$ \\
\hline \multicolumn{6}{|c|}{ Mortalidad } \\
\hline Totalmente afectado & 21 & $4,4 \pm 3,0$ & $19,6 \pm 6,5$ & $773 \pm 1.216$ & $714 \pm 1.703$ \\
\hline Afectación media & 25 & $3,9 \pm 2,6$ & $19,5 \pm 5,7$ & $850 \pm 1.384$ & $650 \pm 1.203$ \\
\hline No afectado & 22 & $5,1 \pm 2,9$ & $16,2 \pm 7,4$ & $56,8 \pm 266$ & $227 \pm 626$ \\
\hline
\end{tabular}

* La clase $10-40 \%$ de fracción de cabida cubierta no ha sido descrita al no considerarse estrictamente bosques.

** Media de los 5 árboles más cercanos al centro de la parcela. 
que aumenta la densidad. Los bosques que no presentaban problemas de mortalidad mostraron la mayor altura del dosel y un diámetro menor que el resto de las clases.

La regeneración en los bosques de ñirre estudiados presenta una gran variabilidad y heterogeneidad espacial, aunque los valores medios, tanto para plántulas procedentes de semilla como procedentes de regeneración vegetativa, indican regeneración abundante (cuadro 1). No obstante, la gran dispersión de los datos indica que hay parcelas con regeneración abundante y parcelas donde prácticamente ésta no existe.

Cartografía de la mortandad en los ecosistemas de ñirre. Los valores de los coeficientes de determinación de las ecuaciones obtenidas entre la mortalidad y la fracción de cabida cubierta con el NDVI fueron en los dos casos superiores al $78 \%$, siendo significativos en ambos casos (cuadro 2).

Cuadro 2. Ecuaciones y estadísticos de las ecuaciones de regresión entre los parámetros estudiados y los valores del índice NDVI (variable independiente) $(\mathrm{n}=68)$.

Equations and statistics of regression equations between parameters studied and the NDVI values $(\mathrm{N}=68)$.

\begin{tabular}{lcccc}
\hline $\begin{array}{l}\text { Variable } \\
\text { dependiente }\end{array}$ & Ecuación & $R$ & $R^{2}$ & $S E$ \\
\hline $\begin{array}{l}\text { Mortandad } \\
\begin{array}{l}\text { Fracción de } \\
\text { cabida cubierta }\end{array}\end{array}$ & $-0,9793+3,3670(\mathrm{NDVI})^{2}$ & 0,92 & $0,85^{* * * *}$ & 0,19 \\
\hline
\end{tabular}

*** $P<0,001$.

Las categorías definidas según el NDVI son significativamente diferentes tanto para la mortalidad $(\mathrm{F}=68,42$; $P<0,001)$ como para la fracción de cabida cubierta (F $=21,62 ; P<0,001)$, aunque las clases de fracción de cabida cubierta de $40-60 \%$ y de $60-80 \%$ no se diferencian significativamente entre ellas (cuadros 3 y 4 ; figuras $2 \mathrm{~A}$ y 2B).

Cuadro 3. Valores medios del índice normalizado de vegetación (NDVI) según categorías de mortalidad y superficie para el año 2002 y 1986. Letras iguales indican pertenencia a un mismo subconjunto según el método para comparaciones múltiples de Tukey $(P<0,05)$.

Normalized Vegetation Index (NDVI) and the three affectation levels and surface for each of the classes in the study area during the period 2002 to 1986. Different letters indicate significant differences between treatments at $P \leq 0.05$ (ANOVA, Tukey test).

\begin{tabular}{lccr}
\hline Nivel de mortalidad & NDVI & $\begin{array}{c}\text { Superficie 2002 } \\
\text { (ha) }\end{array}$ & $\begin{array}{c}\text { Superficie 1986 } \\
\text { (ha) }\end{array}$ \\
\hline Suelo desnudo & $0,24 \mathrm{a}$ & 1.168 & 328 \\
Totalmente afectado & $0,59 \mathrm{~b}$ & 6.825 & 9.684 \\
Afectación media & $0,71 \mathrm{c}$ & 15.955 & 20.216 \\
Sin afectación & $0,80 \mathrm{~d}$ & 10.853 & 4.573 \\
Total & - & 34.801 & 34.801 \\
\hline
\end{tabular}

Cuadro 4. Valores medios del índice normalizado de vegetación (NDVI) según categorías de fracción de cabida cubierta y superficie para el año 2002 y 1986. Letras iguales indican pertenencia a un mismo subconjunto según el método para comparaciones múltiples de Tukey $(P<0,05)$.

Normalized Vegetation Index (NDVI) and the five forest covers and surfaces for each of the classes in the study area during the period 2002 to 1986. Different letters indicate significant differences between treatments at $P \leq 0.05$ (ANOVA, Tukey test).

\begin{tabular}{lccc}
\hline $\begin{array}{l}\text { Fracción de } \\
\text { cabida cubierta }\end{array}$ & NDVI & $\begin{array}{c}\text { Superficie 2002 } \\
\text { (ha) }\end{array}$ & $\begin{array}{c}\text { Superficie 1986 } \\
\text { (ha) }\end{array}$ \\
\hline Suelo desnudo & $0,24 \mathrm{a}$ & 1.168 & 328 \\
$10-40 \%$ & $0,52 \mathrm{~b}$ & 3.331 & 2.604 \\
$40-60 \%$ & $0,63 \mathrm{c}$ & 8.611 & 14.221 \\
$60-80 \%$ & $0,72 \mathrm{~d}$ & 12.874 & 14.006 \\
$80-100 \%$ & $0,79 \mathrm{~d}$ & 8.817 & 3.642 \\
Total & - & 34.801 & 34.801 \\
\hline
\end{tabular}

En el año 2002 la superficie de ñirre con daños de mortalidad medios es la más elevada de las tres categorías (45,8\% de la superficie clasificada). Las zonas donde el arbolado aparece totalmente muerto ocupan una superficie menor, aunque con una importancia relativa grande $(19,6 \%$ de la superficie clasificada). En cuanto a la fracción de cabida cubierta, la mayoría de las masas de ñirre estudiadas tienen una elevada densidad (fcc $>60 \%$ ), con una superficie dentro de esta clase en el año 2002 de 21.691 ha (62,3\% de la superficie clasificada), mientras que las zonas de menor densidad (10-60\% de fracción de cabida cubierta) no llega a las 12.000 ha. La distribución de los bosques en función de la fracción de cabida cubierta ocurre espacialmente siguiendo un patrón parecido a los niveles de mortandad, con una clara orientación noroeste-sureste (figuras 2A y 2B).

La mayor parte de la superficie no ha experimentado cambios en ese periodo, tanto en la categoría de mortalidad $(55,4 \%)$ como en cobertura $(46,6 \%)$ (cuadro 5, figura $2 \mathrm{C}$ ). En segundo lugar se encuentran aquellas superficies en las que las formaciones de ñirre han experimentado una mejoría, bien en sus condiciones de vigor $(32,4 \%)$ o de cobertura $(32,4 \%)$. Las formaciones que experimentaron un empeoramiento son menores, aunque importantes en términos relativos, correspondiendo 10,7\% de la superficie clasificada en cuanto a la mortalidad y $14,1 \%$ de la superficie clasificada en cuanto a la fracción de cabida cubierta (figura 2c). Es importante indicar la desaparición completa del ñirre en 840 ha, lo cual no resultando superficialmente relevante, puede representar un importante cambio en determinadas localidades (cuadro 5; figura 2C).

\section{DISCUSIÓN}

En este trabajo se ha mostrado la utilidad de las imágenes de los sensores Landsat 5 TM y 7 ETM+ para evaluar los 


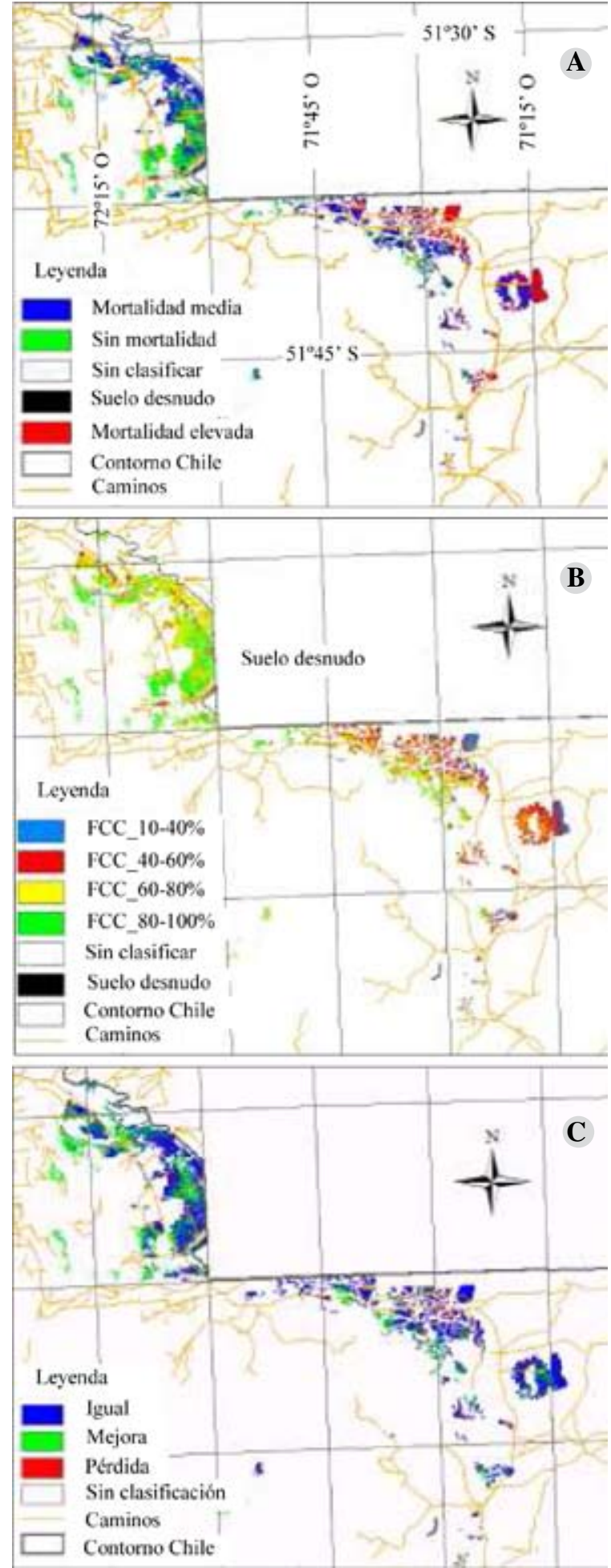

Figura 2. Mapas de los ecosistemas de ñirre a partir de una imagen Landsat-7ETM+. A) niveles de mortalidad, B) valores de fracción de cabida cubierta, C) cambio de los niveles de mortalidad de los ecosistemas de ñirre en el periodo 1986-2002 a partir de dos imágenes Landsat-5TM y 7ETM+.

Map of the Nothofagus antarctica ecosystems using a Landsat-7ETM+ image A) mortality levels, B) forest cover, C) change in mortality levels during the period 1986-2002 using two images Landsat-5TM and 7ETM+.
Cuadro 5. Superficies según categoría de cambio del estado de la vegetación en niveles de mortalidad y fracción de cabida cubierta en el periodo 1986-2002.

Surface according to vegetation change for mortality and forest cover during the period 1986 to 2002

\begin{tabular}{lcc}
\hline Clases & $\begin{array}{c}\text { Niveles de } \\
\text { mortalidad } \\
\text { (ha) }\end{array}$ & $\begin{array}{c}\text { Fracción de } \\
\text { cabida cubierta } \\
\text { (ha) }\end{array}$ \\
\hline Mejora & 11.282 & 12.825 \\
Empeora & 3.734 & 4.938 \\
Sin cambios & 19.292 & 16.248 \\
Ajustes & 493 & 790 \\
\hline
\end{tabular}

niveles de mortalidad del arbolado en bosques de ñirre en un área de la XII Región de Chile, así como el cambio temporal experimentado en el periodo 1986-2002. Los estudios sobre cartografía de bosque de ñirre, en particular en esta zona del sur de Chile, son muy limitados, reduciéndose a trabajos mediante fotografías aéreas (Dollenz 1983) o a clasificaciones de la vegetación mediante imágenes del satélite Landsat TM (Dollenz y Santana 2000, Arqueros et al. 2001). Sin embargo, no existen trabajos aplicados a la evaluación de procesos de mortalidad, y en particular a la detección de cambios, frecuentes en otros contextos ecológicos (Wulder et al. 2006).

Los bosques de ñirre estudiados en este trabajo corresponden a formaciones achaparradas, dentro del gradiente altitudinal de la especie presente en la Patagonia chilena (Donoso 1993, Cruz et al. 2002). El diámetro normal disminuye y la altura del arbolado aumenta a medida que las masas son más densas o presentan niveles más bajos de mortalidad. Estos resultados coinciden con los obtenidos por la tipificación realizada por CONAF (1978), donde las masas más densas correspondieron a bosques de ñirre compuestos por individuos de porte arbóreo de aproximadamente 5 a $6 \mathrm{~m}$ de altura, que iban reduciendo su talla a medida que bajaba la densidad, en general de talla menor a los 3-4 m, y con un estrato arbustivo más denso.

Existen numerosos antecedentes del uso de imágenes Landsat en estudios de mortalidad de arbolado, en particular de plagas de defoliadores (Heikkilä et al. 2002, Olthof et al. 2004). Los resultados obtenidos en este trabajo refuerzan el valor del índice NDVI para el seguimiento del estado fitosanitario de masas forestales, en particular si se trabaja con un número limitado de niveles de defoliación, que aunque suponen una simplificación del número de clases utilizado en la asignación del estado sanitario de los bosques (Ferretti 1994), reflejan de manera más operativa la defoliación de la masa. No obstante, este trabajo no ha realizado una validación de la cartografía obtenida, por ejemplo mediante una matriz de confusión. Sin embargo, el trabajo sigue aportando una información muy interesante como una primera aproximación a la evaluación de procesos de cambio de vegetación en vege- 
tación patagónica, que permita profundizar en un trabajo más amplio en el futuro.

En la superficie estudiada se observó que existe una importante incidencia de procesos de mortalidad del arbolado, aunque la superficie de arbolado muerto es relativamente pequeña. En cuanto a la fracción de cabida cubierta, la mayor parte de los bosques estudiados tiene una elevada densidad. No existen valores comparativos de superficie según categorías de mortalidad en este tipo de bosques, aunque los datos parecen indicar la importancia relativa que tienen estos procesos en este tipo de bosques. La mortalidad de las formaciones de Nothofagus spp. ha sido estudiada en las últimas décadas (Veblen et al. 1996a, Kitzberger y Veblen 1999, Veblen et al. 2004), si bien no se han encontrado estudios sobre su importancia superficial a lo largo de gradientes ambientales. El cambio de la mortalidad experimentado por los bosques de ñirre entre los años 1986 y 2002 no muestra un incremento de la superficie afectada por mortalidad; por el contrario, pudo observarse una tendencia a mejorar el estado de los bosques de ñirre tanto en vigor como en fracción de cabida cubierta. No obstante, puntualmente en algunas localidades sí puede observarse un progresivo deterioro de estos bosques, e incluso su completa desaparición. Esta situación estaría en consonancia con los resultados presentados por diferentes autores que indican que no se está produciendo un deterioro de los bosques patagónicos (Veblen y Lorenz 1988, Veblen y Markgraf 1988, Veblen et al. 2004). El proceso de mortalidad parece derivarse de la apertura de la frontera agrícola mediante el fuego a mediados del siglo XIX y de la regeneración de formaciones puras o casi puras de ñirre como consecuencia de su gran capacidad de producir múltiples rebrotes de raíz (Donoso 1993), y que han dominado los rodales quemados a lo largo de varias décadas (Veblen y Lorenz 1987, 1988, Kitzberger et al. 1997). La supresión del fuego, seguida de un aprovechamiento ganadero intensivo que impide la regeneración, ha podido favorecer los fenómenos de senescencia (Veblen y Lorenz 1988, Relva y Veblen 1998, Raffaele y Veblen 2001). Los datos de regeneración observados en este trabajo parecen confirmar el efecto negativo de la presión ganadera, no tanto en la densidad de individuos como en su mal estado vegetativo y de desarrollo. Este proceso se agravaría en zonas más próximas a la estepa, debido a una mayor presión antrópica y climática (Veblen y Lorenz 1988, Burns 1993, Villalba y Veblen 1998, Veblen et al. 1999).

Los resultados de este trabajo parecen reforzar esa hipótesis, en contra de las teorías que justificaban dicho proceso por una tendencia a condiciones climáticas más adversas ("hipótesis de Kalela", Veblen y Lorenz 1988). Sin embargo, no debe descartarse la posibilidad de que el actual cambio climático pueda modificar los patrones de regeneración de las especies forestales en el ecotono bosque-estepa (Villalba y Veblen 1998, Daniels y Veblen 2000, Suárez et al. 2004). La vegetación más afectada por procesos de mortandad se encuentra en la transición de la vegetación con la estepa, donde hay una tendencia al empeoramiento, y en particular en terrenos con fuertes cargas ganaderas, donde la vegetación se encuentra en muchos casos totalmente muerta. Esto supone que localmente se está produciendo la pérdida de rodales de ñirre de gran valor ecológico, y cuya conservación debería tenerse presente. Esta situación justifica que se necesite desarrollar medidas de gestión para los bosques de ñirre en el sur de Chile que frenen este proceso de degradación y aseguren su supervivencia en el tiempo.

Los bosques de ñirre del sur de Chile presentan en la actualidad diferentes niveles de mortalidad, como resultado de los procesos de dinámica de la vegetación asociados a un uso relativamente reciente de estos bosques por parte del hombre. Los estudios a escala de paisaje podrían ayudar a comprender la dinámica de estos procesos, donde el uso de sensores remotos constituye una pieza clave para la elaboración de cartografía a escala local e incluso regional. Esta información permite a su vez estudiar el patrón de cambio temporal, que junto a estudios de dinámica de la vegetación a escala de rodal permiten una interpretación más completa y compleja de la dinámica de estos bosques, y de los fenómenos de mortandad y senescencia observados (Veblen et al. 2004). En particular, sería necesario un mejor conocimiento de la dinámica del ecotono bosque-estepa a lo largo de diferentes escalas espaciales y temporales, junto a los estudios de autoecología del ñirre.

\section{AGRADECIMIENTOS}

Este trabajo ha sido posible gracias al convenio de colaboración entre la Corporación Forestal de Chile (CONAF) y la Universidad de Córdoba, a través del Programa Propio del Vicerrectorado de Relaciones Exteriores. También se agradece la colaboración de todas las personas que hicieron posible el trabajo de campo.

\section{REFERENCIAS}

Arqueros M, C Di Bella, C Movia. 2000. Determinación de diferentes tipos de bosques de ñire (Nothofagus antarctica) a partir de la utilización de imágenes satelitales Landsat TM, fotografías aéreas y trabajo de campo, en el Paraje Trompul, Parque Nacional Lanín (Argentina). IX Simposio Latinoamericano de Percepción Remota. SELPER. Puerto Iguazú, Misiones. Argentina.

Burns BR. 1993. Fire-induced dynamics of Araucaria araucana - Nothofagus antarctica forest in the southern Andes. Journal of Biogeography 20: 669-685.

Chuvieco E. 1996. Fundamentos de Teledetección especial. Madrid, España. Rialp. 453 p.

Collado L. 2001. Los bosques de la Tierra del Fuego. Análisis de su estratificación mediante imágenes satelitales para el inventario forestal de la provincia. Multiequina 10: 1-16. 
CONAF (Corporación Nacional Forestal, CL). 1978. Antecedentes forestales XII Región de Magallanes y Antártica chilena. Punta Arenas, Chile. Universidad de Chile. 95 p.

CONAF (Corporación Nacional Forestal, CL). CONAMA (Corporación Nacional del Medio Ambiente, CL). 1997. Catastro y Evaluación de los Recursos Vegetacionales Nativos de Chile. Santiago, Chile. Universidad Austral de Chile, Pontificia Universidad Católica de Chile, Universidad Católica de Temuco. 93 p.

Cruz G, A Promis, R Caprile, S Donoso, G Cabello. 2002. Caracterización estructural y dasométrica de los bosques de producción de coihue de Magallanes en la XII Región. Depto. de Silvicultura, Fac. de Ciencias Forestales, Universidad de Chile. Consultado 10 de mayo 2004. Disponible en http://www.forestal.uchile.cl/proyectofondefd02i1080/PDF/ caracterizacion.pdf.

Daniels LD, TT Veblen. 2000. ENSO effects on temperature and precipitation of the Patagonian-Andean region: Implications for biogeography. Physical Geography 21: 223-243.

Díaz C, R Roberts. 1960. Los grandes grupos de suelos de la Provincia de Magallanes. Agricultura Técnica 19-20: 227-308.

Dollenz O. 1983. Fitosociología de la Reserva Forestal "El Parrillar", Península de Brunswick, Magallanes. Anales del Instituto de la Patagonia 14: 109-118.

Dollenz O, A Santana. 2000. Clasificación y distribución espacial de la vegetación de Cabo Negro (Magallanes, Chile) utilizando imágenes satelitales. Anales del Instituto de la Patagonia 28: 51-56.

Donoso C. 1981. Tipos forestales de los bosques nativos de Chile. Santiago, Chile, CONAF/PNUD/FAO, Programa de Investigación y Desarrollo Forestal. 82 p. (Documento de Trabajo $\mathrm{N}^{\mathrm{o}} 38$ ).

Donoso C. 1993. Bosques templados de Chile y Argentina. Variación, estructura y dinámica. Santiago, Chile. Editorial Universitaria. $484 \mathrm{p}$.

Ekstrand S. 1994. Assessment of forest damage with Landsat TM: Correction for varying forest stand characteristics. Remote Sensing of Environment 47: 291-302.

Ferretti M. 1994. Especies forestales mediterráneas. Guía para la evaluación de las copas. CEE-UN/ECE. Bruselas, Ginebra. $93 \mathrm{p}$.

GOFC. 1999. A Strategy for Global Observation of Forest Cover. 58 p. (Gofc-gold Report 2). Consultado 15 de mayo 2004. Disponible en www.fao.org/GTOS/gofc-gold/docs/ GOLD_2.pdf

González C, J Martínez, M Pardo, J Solana. 1993. Técnicas de Muestreo en la Evaluación de Recursos Forestales. Madrid, España. Fundación Conde del Valle de Salazar. 239 p.

Heikkilä J, S Nevalainen, T Tokala. 2002. Estimating defoliation in boreal coniferous forest by combining Landsat TM, aerial photographs and field data. Forest Ecology and Management, 158: 9-23.

INIA (Instituto Nacional de Investigaciones Agrarias). 1989. Mapa Agroclimático de Chile. Santiago, Chile. Ministerio de Agricultura. 221 p.

Innes J. 1993. Forest health. Its assessment and status. CAB Int. Wallingtord, UK. 677 p.

Kitzberger T, T Veblen, R Villalba. 1997. Climatic influences on fire regimes along a rain forest-to-xeric woodland gradient in northern Patagonia, Argentina. Journal of Biogeography 24: $35-47$
Kitzberger T, T Veblen. 1999. Fire-induced changes in northern Patagonian landscapes. Landscape Ecology 14: 1-15.

Klap J, J Oude Voshaar, W de Vries, J Erisman 2000. Effects of environmental stress on forest crown condition in Europe. Part IV: Statistical analysis of relationships. Water, Air and Soil Pollution. 119: 387-420.

Kurtz D, R Vanni, H Ligier. 2001. Estudios de la vegetación del Parque Nacional Mburucuyá, mediante imágenes satelitales y datos de campo. INTA-EEA (Corrientes Recursos Naturales), Instituto de Botánica del Nordeste (IBONE-CONICET), Corrientes, Argentina. Consultado 21 de enero 2004. Disponible en http://www.unne.edu.ar/Web/cyt/cyt/2001/6Biologicas/B-024.pdf

Lara A, V Sandoval, C Prado, G Cruz, Y Martínez, P Añazco. 1995. Determinación de stocks de bosque nativo. Valdivia, Chile. Proyecto Banco Central-Universidad Austral de Chile. 145 p.

Lo T, F Scarpace, T Lillesand. 1986. Use of multitemporal spectral profiles in agricultural land-cover classification. Photogrammetric Engineering and Remote Sensing 52: 397-399.

Manion P. 1991. Tree disease concepts. Prentice Hall. Englewood Cliffs. 402 p.

Markham B, J Barker. 1986. Landsat MSS and TM Post-Calibration Dynamic Ranges, Exoatmospheric Reflectances and At Satellite Temperatures. EOSAT Landsat Technical Notes 1: 3-5.

Olthof I, D King, R Lautenschilager. 2004. Mapping deciduous forest ice storm damage using Landsat and environmental data. Remote Sensing of the Environment 89: 484-496.

Pisano E. 1997. Los bosques de la Patagonia Austral y Tierra del Fuego chilenas. Anales Instituto de la Patagonia 25: 9-19

Raffaele E, T Veblen. 2001. Effects of cattle razing on early postfire regeneration of matorral in northwest Patagonia, Argentina. Natural Areas Journal 21: 243-249.

Ramírez C, M Correa, H Figueroa, J San Martín. 1985. Variación del hábito y hábitat de Nothofagus antarctica en el sur de Chile. Bosque 2: 55-73.

Rebertus A, T Veblen, T Kitzberger. 1993. Gap formation and dieback in Fuego-Patagonian Nothofagus forests. Phytocoenologia 23: 581-599.

Relva M, T Veblen. 1998. Impacts of introduced large herbivores on Austrocedrus chilensis forests in northern Patagonia, Argentina. Forest Ecology and Management 108: 27-40.

Segura M, G Trincado. 2003. Cartografía digital de la Reserva Nacional Valdivia a partir de imágenes satelitales Landsat TM. Bosque vol. 24 (2): 43-52.

SIAN. (1998) Subsecretaría de Recursos Naturales y Ambiente Humano. Dirección de Protección Ambiental San Martín 1401 Ushuaia. Tierra del Fuego. Argentina. Consultado 12 abril 2004. Disponible en http://www.medioambiente.gov.ar.

Silla F, S Fraver, A Lara, T Allnutt, A Newton 2002. Regeneration and stand dynamics of Fitzroya cupressoides (Cupressaceae) forests of southern Chile's Central Depression. Forest Ecology and Management 165: 213-234.

Song C, C Woodcock, K Seto, M Lenney, S McComber. 2001. Classification and Change Detection Using Landsat TM Data: When and How to Correct Atmospheric Effects? Remote Sensing of Environment 2: 230-244.

Suárez M, L Ghermandi, T Kitzberger. 2004. Factors predisposing episodic drought-induced tree mortality in Nothofagus site, climatic sensitivity and growth trends. Journal of Ecology 92: 954-966. 
Veblen T, C Donoso, T Kitzberger, A Rebertus. 1996a. Ecology of southern Chilean and Argentinean Nothofagus forests. In Veblen T, R Hill, J Read eds. The Ecology and Biogeography of Nothofagus Forests. Yale University Press, New Haven, Connecticut. p. 293-353.

Veblen T, T Kitzberger, B Burns, A Rebertus. 1996b. Perturbaciones y regeneración en bosques andinos del sur de Chile y Argentina. In Armesto J, M Arroyo, C Villagrán eds. Ecología del Bosque Nativo de Chile. Universidad de Chile. p 169-198.

Veblen T, T Kitzberger, R Villalba, J Donnegan. 1999. Fire history in northern Patagonia: The roles of humans and climatic variation. Ecological Monographs 69: 47-67.

Veblen T, D Lorenz. 1987. Post-fire stand development of AustrocedrusNothofagus forests in Patagonia. Vegetatio 73: 113-126.

Veblen T, D Lorenz. 1988. Recent vegetation changes along the forest/steppe ecotone in northern Patagonia. Annals of the Association of American Geographers 78: 93-111.

Veblen T, V Markgraf. 1988. Steppe expansion in Patagonia? Quaternary Research 30: 331-338.
Veblen T, T Kitzberger, R Villalba. 2004. Nuevos paradigmas en ecología y su influencia sobre el conocimiento de la dinámica de los bosques del sur de Argentina y Chile. In Arturi M, J Frangi, J Goya eds. Ecología y Manejo de Bosques de Argentina. Editorial de la Universidad Nacional de La Plata, La Plata, Argentina. p. 1-48.

Villalba R, T Veblen. 1998. Influences of large-scale climatic variability on episodic tree mortality at the foreststeppe ecotone in northern Patagonia. Ecology 79: 2624-2640.

Willhauck G 2000. Comparison of object oriented classification techniques and standard image analysis for the use of change detection between SPOT multispectral satellite images and aerial photos. ISPRS, 33: 35-42.

Wulder M, C Dymond, J White, D Leckie, A Carroll. 2006. Surveying mountain pine beetle damage of forests: A review of remote sensing opportunities. Forest Ecology and Management 221: 27-41. 